\title{
Retraction Note to: Organizational Ethics
}

Marie-Catherine Letendre

Marymount International, Rome, Italy

Bioethics International, New York, NY, USA

\section{Retraction Note to: "Organizational Ethics" in:}

H. ten Have (ed.), Encyclopedia of Global Bioethics,

https://doi.org/10.1007/978-3-319-09483-0_320

The Editor has retracted this Reference Work Entry due to substantial overlap with a previously published article [1]. Marie-Catherine Letendre agrees to this retraction.

\section{References}

1. Roberts, R. (2009). The rise of compliance-based ethics management: Implications for organizational ethics. Public Integrity, 11(3), 261-278. 